\title{
PENGEMBANGAN SISTEM TRACER ALUMNI PRODI ILMU HUKUM UIN SUNAN KALIJAGA MELALUI KUESIONER DARING
}

\section{TRACER SYSTEM DEVELOPMENT ALUMNI OF LAW DEPARTMENT UIN SUNAN KALIJAGA THROUGH ONLINE QUESTIONNAIRES}

\author{
Alfianita Atiq Junaelis Subarkah ${ }^{1}$, Ade Umar Ramadhan ${ }^{2 *}$ \\ ${ }^{1}$ Prodi Ilmu Hukum, UIN Sunan Kalijaga Yogyakarta \\ ${ }^{2}$ Teknik Informatika, UIN Sunan Kalijaga Yogyakarta \\ Jalan Laksda Adisucipto, Papringan, Caturtunggal, Kecamatan Depok, \\ Kabupaten Sleman, Daerah Istimewa Yogyakarta 55281 \\ *Email: 18106050027@student.uin-suka.ac.id \\ (Diterima 29-08-2021; Disetujui 15-09-2021)
}

\begin{abstract}
ABSTRAK
Program tracer study dilakukan agar mengetahui bagaimana karir lanjutan dari alumni Ilmu Hukum UIN Sunan Kalijaga. Tidak hanya itu, penggunaan tracer study juga dapat dilakukan untuk menjaring alumni yang masih pada tahap pencarian kerja, atau melanjutkan pendidikan. Tujuan lainnya adalah untuk mengetahui informasi mengenai hasil pendidikan dan kompetensi lulusan ketika telah berhadapan dengan dunia kerja, dunia usaha dan industri. Hasil dari tracer study dapat digunakan sebagai bahan evaluasi bagi program studi dalam hal pembelajaran, sarana prasaran, dan pengalaman belajar alumni. Kegiatan tracing yang dilakukan terhadap alumni Ilmu Hukum lulusan tahun 2018 sampai dengan Juni 2021 menggunakan kuesioner yang dapat diisi secara daring agar menjangkau alumni secara keseluruhan, sehingga tidak memerlukan adanya tatap muka atau duduk bersama yang dikarenakan situasi pandemi COVID-19. Selain itu, alumni sudah tidak bertempat tinggal dalam satu daerah yang sama, karenanya metode tracing dengan kuesioner daring lebih tepat untuk digunakan. Berdasarkan tiga hal indikator yaitu penilaian pembelajaran, penilaian fasilitas belajar, dan penilaian pengalaman belajar memperlihatkan bahwa penilaian terhadap fasilitas belajar memiliki respon "kurang" dengan porsi yang paling besar jika dibandingkan dengan dua penilaian lainnya. Tahapan yang telah dilakukan pada program tracer study yaitu mulai dari penyusunan kuesioner daring, pendataan alumni dan informasi kontak, pengisian kuesioner, pembuatan akun media sosial alumni ilmu hukum, dan pengolahan data. Lebih daripada itu, tujuan kegiatan ini secara umum dilakukan untuk memberikan pengetahuan dan informasi mengenai hasil pendidikan dan kompetensi lulusan dengan dunia kerja juga menjaring alumni yang masih dalam tahap pencarian kerja atau melanjutkan pendidikan.
\end{abstract}

Kata kunci: Tracer, Alumni, Kuesioner, Daring, Data

\section{ABSTRACT}

The tracer study program was carried out to find out how the advanced career of the alumni of UIN Sunan Kalijaga majoring in Law studies. Not only that, the use of tracer studies can also be carried out to recruit alumni who are still in the job search stage or continue their education. Another objective is to find out information about educational outcomes and graduate competencies when dealing with the world of work, business and industry. The results of the tracer study can be used as evaluation material for study programs in terms of learning, infrastructure, and alumni learning experiences. Tracing activities carried out on alumni of Law Studies graduates from 2018 to June 2021 use questionnaires that can be filled out online in order to reach alumni, so there is no need for face-to-face or sitting together due to the COVID-19 pandemic situation. In addition, alumni no longer live in the same area, therefore the tracing method with online questionnaires is more appropriate to use. Based on three indicators, namely learning assessment, learning facility assessment, and learning experience assessment, it shows that the assessment of learning facilities has a "less" response with the largest portion compared to the other two assessments. Moreover, the purpose of this activity is generally to provide knowledge and information regarding educational outcomes and graduate competencies with the world of work as well as to recruit alumni who are still in the job search stage or continuing their education.

Keywords: Tracer, Alumni, Questionnaires, Online, Data 


\section{PENDAHULUAN}

Salah satu wujud dari tridarma perguruan tinggi adalah melakukan pengabdian pada masyarakat melalui Kuliah Kerja Nyata. UIN Sunan Kalijaga memiliki beberapa jenis Kuliah Kerja Nyata (KKN), yakni KKN Reguler, Mandiri, dan Tematik. KKN Tematik ialah jenis KKN yang memiliki suatu tema dan tujuan tertentu, misalnya di bidang informasi dan teknologi seperti yang dijalankan oleh kelompok KKN 105 Tracer FSH. Kelompok KKN Tracer mengusung tema pengembangan sistem tracer alumni Fakultas Syari'ah dan Hukum UIN Sunan Kalijaga, yang kemudian berfokus pada Program Studi Ilmu Hukum.

Fakultas Syari'ah dan Hukum UIN Sunan Kalijaga sudah berdiri sejak tahun 1960 ketika nama Institusi Agama Islam Negeri masih disandang oleh UIN Sunan Kalijaga. Hingga kini telah terdapat lima jurusan/program studi Strata 1 yang ditawarkan, diantaranya adalah Ilmu Hukum, Hukum Keluarga Islam, Hukum Tata Negara, Hukum Ekonomi Syari'ah, dan Perbandingan Mazhab. Program Studi Ilmu Hukum menjadi jurusan yang terakhir lahir dari Fakultas Syari'ah dan Hukum pada tahun 2009. Meskipun menjadi program studi termuda, tetapi Ilmu Hukum tetap senantiasa konsisten meningkatkan kualitas, baik dari segi akademik, maupun sarana prasarana.

Terlepas dari berbagai pengertian hukum secara luas, ilmu hukum dapat diartikan sebagai ilmu yang mempelajari bagaimana hukum menjadi aturan yang mengikat atas tindakan dan perilakunya masyarakat, yang memiliki sanksi terhadap pelanggarannya. Mengutip pendapat Drs. E. Utrecht, S.H. bahwa hukum adalah himpunan peraturan yang berisi perintah dan larangan untuk mengurus tata tertib dari masyarakat, oleh karenanya harus dipatuhi (Kansil 1989). Sarjana Ilmu Hukum dibentuk menjadi insan yang dapat memahami hukum dengan baik, sehingga ketika telah terjun ke masyarakat diharapkan dapat menjadi bagian dari para penegak hukum yang berintegritas. Tidak hanya mengambil peran di dalam penegakan hukum, sarjana ilmu hukum juga dapat akademis, atau ahli di bidangnya. Ketika tidak secara langsung turut serta berprofesi di bidang hukum pun, misal dengan jalan berwirausaha, mereka sudah memahami hukum dan dapat menerapkannya dalam usaha, karir maupun kehidupan.

Untuk dapat mengetahui bagaimana karir lanjutan dari alumni Ilmu Hukum UIN Sunan Kalijaga dapat dilakukan dengan tracer study. Tidak hanya itu, penggunaan tracer study juga dapat dilakukan untuk menjaring alumni yang masih pada tahap pencarian kerja, atau melanjutkan pendidikan. Tujuan lainnya adalah untuk mengetahui informasi mengenai hasil pendidikan dan kompetensi lulusan ketika telah berhadapan dengan dunia kerja, dunia 
usaha dan industri (Fajaryati, et al. 2015). Hasil dari tracer study dapat digunakan sebagai bahan evaluasi bagi program studi dalam hal pembelajaran, sarana prasaran, dan pengalaman belajar alumni. Perbaikan proses pembelajaran dan sarana prasarana yang dilakukan, akan meningkatkan mutu dan kualitas pendidikan dari UIN Sunan Kalijaga sebagai salah satu perguruan tinggi negeri. Dengan demikian, setelah lulus dari Program Studi Ilmu Hukum, para Sarjana Ilmu Hukum dapat memberikan manfaat bagi masyarakat dan juga tata hukum Indonesia. Selain itu, hasil dari tracer study juga dapat menjadi materi penilaian akreditasi program studi yang dilakukan setiap kurun waktu tertentu, karena hasil tracer study mampu menyediakan data alumni yang up to date mengenai jenjang lanjutan alumni setelah lulus dari UIN Sunan Kalijaga.

Berangkat dari latar belakang tersebut, kelompok KKN 105 Tracer FSH menyusun program kerja berkenaan dengan tracer study yang sasarannya adalah alumni Program Studi Ilmu Hukum, dengan spesifikasi tahun kelulusan 2018 sampai dengan Juni 2021. Kelompok KKN 105 Tracer FSH terdiri atas mahasiswa dengan disiplin ilmu berbedabeda, seperti dari bidang Hukum, Teknik Informatika, Psikologi, Manajemen Dakwah, oleh karenanya dapat menerapkan bidang keilmuan masing-masing dalam kegiatan tracing alumni.

\section{BAHAN DAN METODE}

Kegiatan tracing yang dilakukan terhadap alumni Ilmu Hukum lulusan tahun 2018 sampai dengan Juni 2021 menggunakan kuesioner yang dapat diisi secara daring agar menjangkau alumni secara keseluruhan, sehingga tidak memerlukan adanya tatap muka atau duduk bersama dikarenakan situasi pandemi COVID-19. Selain itu, alumni sudah tidak bertempat tinggal dalam satu daerah yang sama, karenanya metode tracing dengan kuesioner online lebih tepat untuk digunakan. Selama pelaksanaan kegiatan tracing, tahapan yang dilakukan ialah: 1) Menyusun kuesioner online; 2) Melakukan pendataan mengenai nama alumni dan kontak yang bisa dihubungi; 3) Menghubungi alumni untuk diminta mengisi kuesioner; 4) Membuat akun media sosial khusus alumni Ilmu Hukum; 5) Mengolah seluruh hasil informasi yang telah diberikan melalui kuesioner.

\section{HASIL DAN PEMBAHASAN}

Kegiatan tracer study dimulai dengan penyusunan pertanyaan kuesioner dan pembuatan form online yang akan dibagikan. Materi pertanyaan disesuaikan dengan keperluan perbaikan pendidikan oleh program studi, sebagaimana tujuan dari tracer study 
adalah untuk memberikan insight bagi Universitas mengenai proses pembelajaran dari program studi dan bagaimana hasil dari pembelajaran tersebut bagi para lulusan dalam berhadapan dengan dunia kerja, usaha, dan masyarakat secara luas. (Dorji 2020)

\section{Penyusunan Kuesioner Online}

Kuesioner berisi pertanyaan-pertanyaan mengenai data yang perlu dihimpun untuk keperluan tracer study melalui Google Form. Pola pertanyaan dibagi menjadi tiga macam, yakni form informasi data pribadi, karir lanjutan, dan penilaian proses belajar mengajar pada Program Studi Ilmu Hukum.

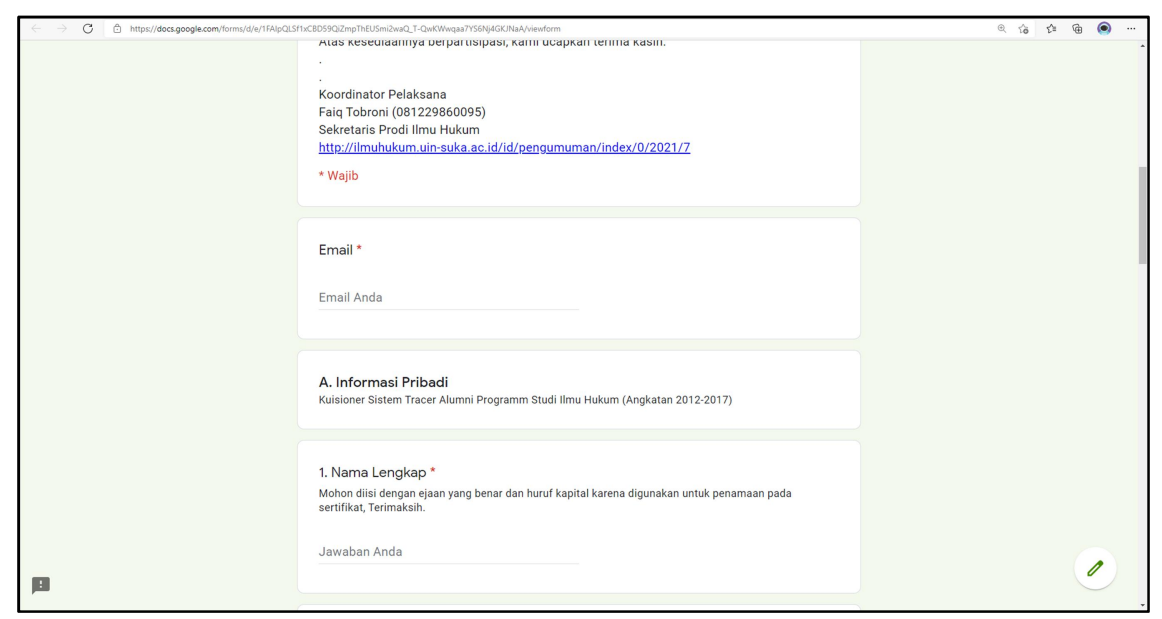

Gambar 1. Form Informasi Data Pribadi

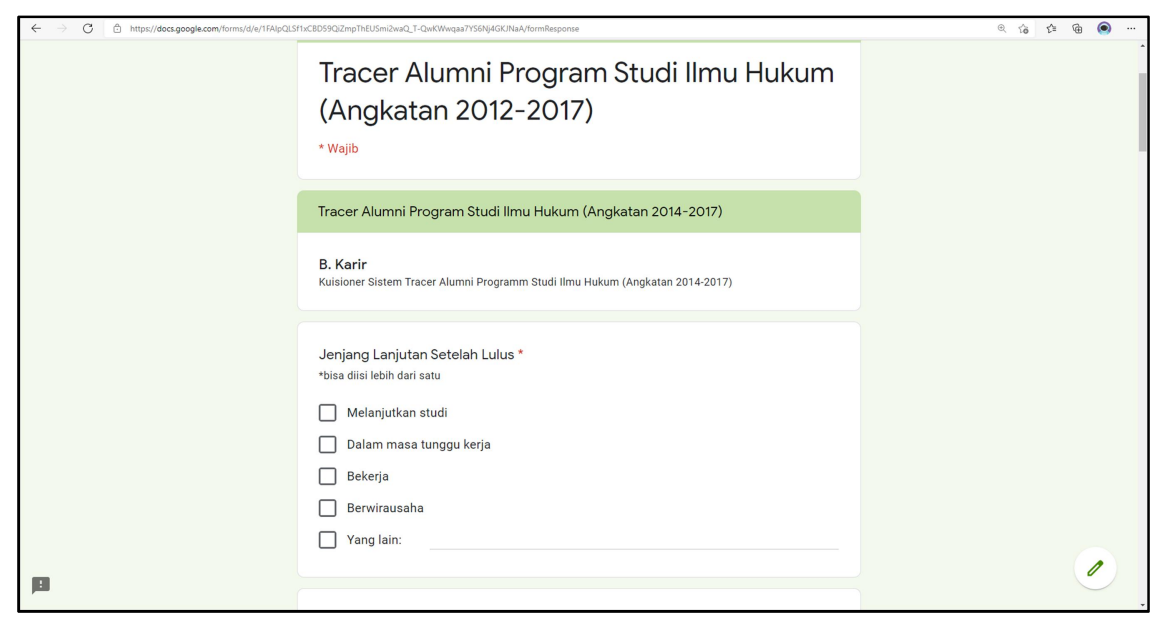

Gambar 2. Form Karir Lanjutan 


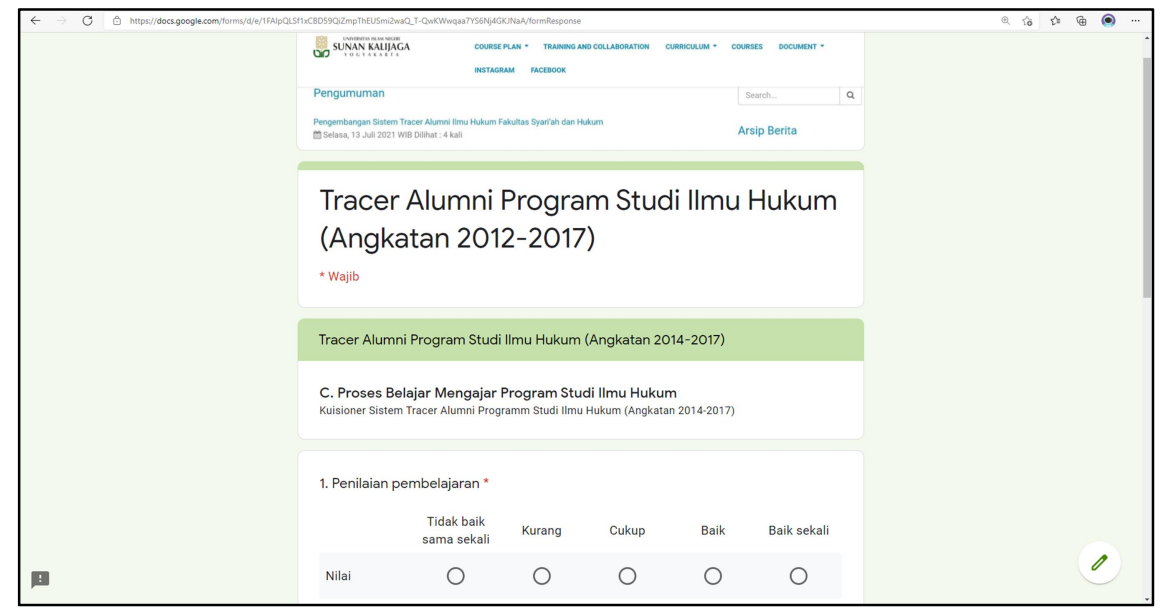

Gambar 3. Form Penilaian Proses Belajar Mengajar

\section{Pendataan Alumni dan Informasi Kontak}

Tahapan selanjutnya adalah menghimpun data alumni Program Studi Ilmu Hukum dan kontak yang bisa dihubungi. Pada tahapan ini, kontak diperoleh dari data milik Program Studi yang terakhir diberikan oleh alumni ketika masih berstatus mahasiswa. Terdapat sebanyak 296 orang yang tercatat sebagai angkatan 2012-2017 dengan tahun kelulusan 2018-2021. Sebanyak 296 orang ini kemudian dihubungi melalui nomor kontak terakhir melalui aplikasi Whatsapp, dan jika nomor tidak dapat dihubungi akan dicoba menghubungi melalui sosial media lainnya seperti Instagram, Facebook, dan e-mail.

\section{Pengisian Kuesioner}

Setelah berhasil dihubungi, alumni akan diminta menjawab pertanyaanpertanyaan yang telah disusun dalam kuesioner online melalui Google Form. Mereka wajib menginformasikan mengenai data diri, lalu jenjang lanjutan yang sedang dijalani. Jenjang lanjutan yang dijalani dapat berupa bekerja, berwirausaha, melanjutkan studi, atau pada masa pencarian kerja. Kemudian, mereka diminta juga untuk mengisi penilaian pengalaman belajar selama menjadi mahasiswa di Program Studi Ilmu Hukum.

Sebagai penghargaan atau apresiasi atas kesediaan dari alumni mengisi kuesioner online ini kemudian diberikan sertifikat resmi dari Program Studi Ilmu Hukum yang sudah ditandatangani oleh Ketua Program Studi dan Dekan Fakultas Syari'ah dan Hukum UIN Sunan Kalijaga. 


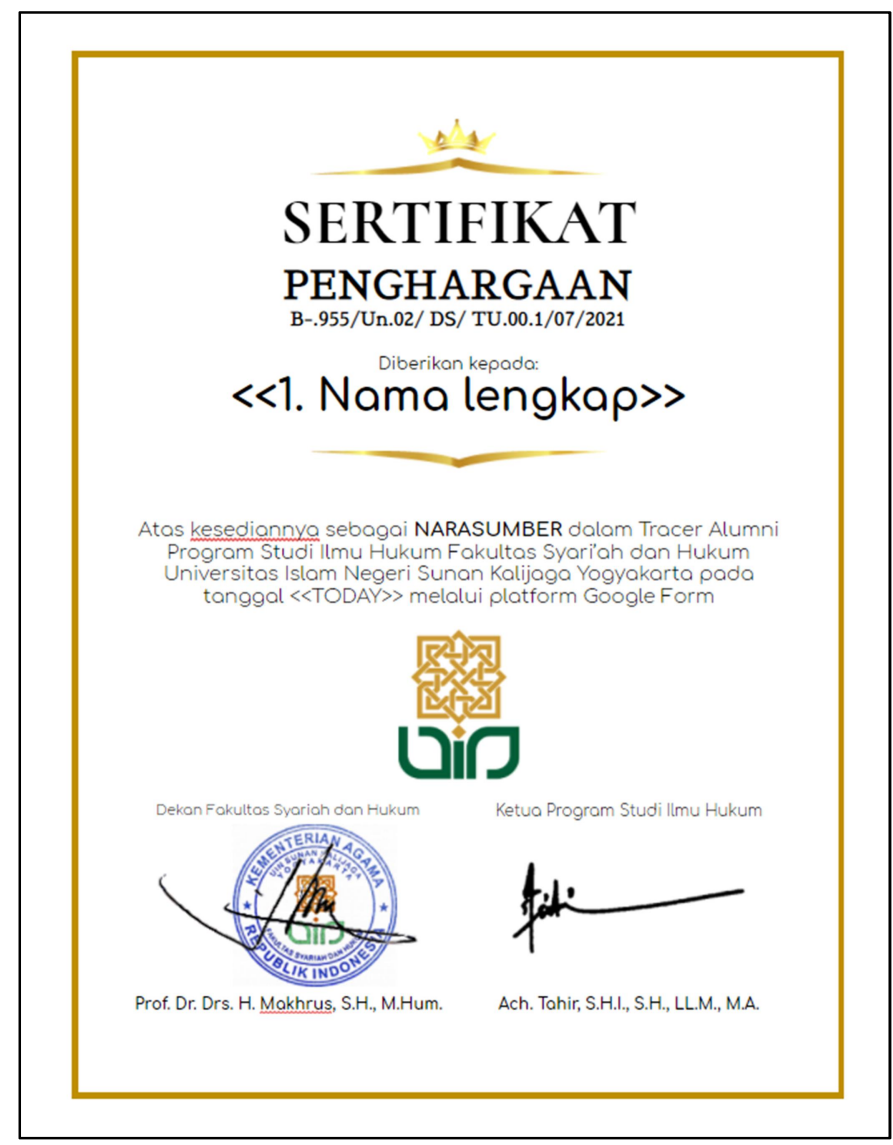

Gambar 4. Sertifikat Apresiasi Kegiatan Tracing

\section{Pembuatan Akun Media Sosial Alumni Ilmu Hukum}

Demi tetap terjaganya kontak antara program studi dan alumni maka perlu dibuat akun media sosial khusus alumni Program Studi Ilmu Hukum. Untuk itu kemudian dibuatlah akun instagram dengan username@AlumniIHUINSuka. Akun ini selanjutnya akan diserahkan kepengurusannya pada program studi yang ke depannya dapat digunakan sebagai sarana berbagi informasi pekerjaan atau informasi lainnya yang berkaitan dengan alumni.

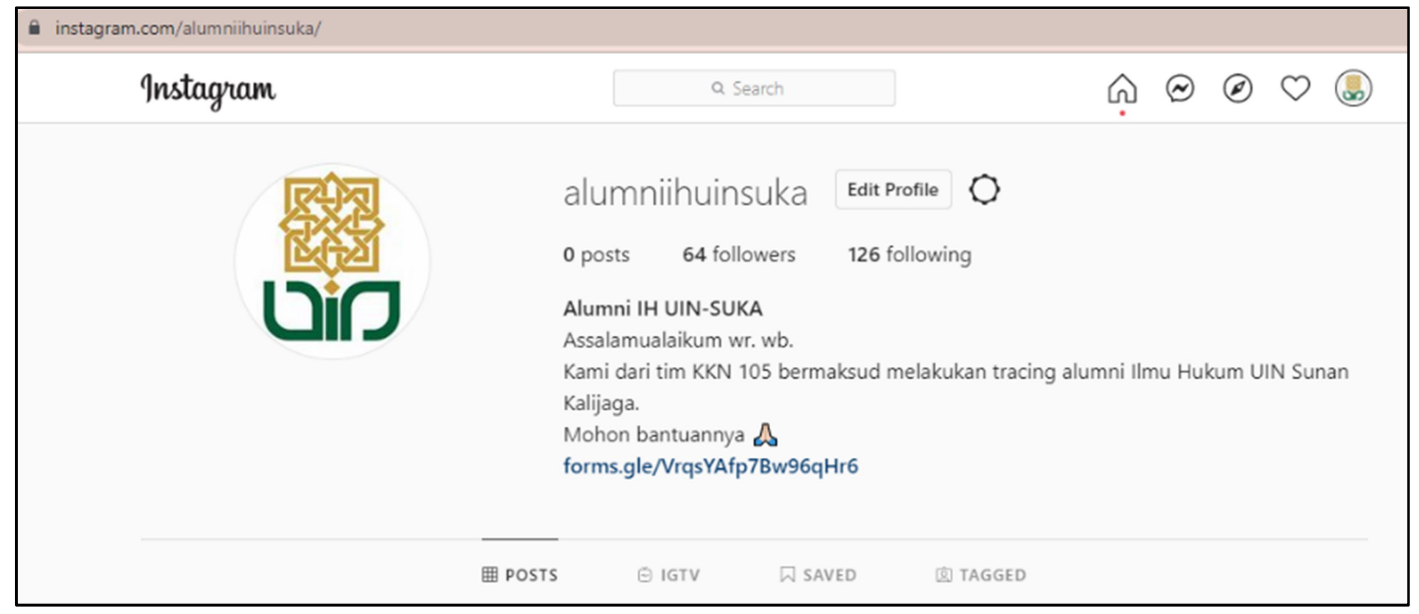

Gambar 5. Akun Instagram@AlumniIHUINSuka 


\section{Pengolahan Data}

Setelah proses pengisian kuesioner online selesai, form lalu ditutup. Dari jawaban-jawaban kuesioner yang diproses kemudian diolah menjadi data alumni Program Studi Ilmu Hukum. Sebanyak 167 jawaban diterima, tetapi hanya 156 yang valid karena adanya kesalahan teknis penginputan dari alumni. Oleh karena itu, dari 296 alumni dengan tahun kelulusan 2018-2021 yang dihubungi, hanya 156 orang yang memberikan feedback dan mengisi kuesioner, ini membuat total response rate hanya tercapai 52,7\%. Mengingat ini adalah KKN Tematik pertama yang bertemakan tracing alumni, maka sudah dapat dikatakan berhasil dan memenuhi target yang diharapkan.

Tracer study yang dilakukan terhadap Program Studi Ilmu Hukum, Fakultas Syari'ah dan Hukum, Universitas Islam Negeri Sunan Kalijaga didapatkan data dari jumlah alumni yang dapat dihubungi dari tahun 2012-2017 terdapat 269 orang, sedangkan yang mengisi kuesioner sebanyak 156. Dari data yang sudah dihimpun bahwa program tracer study yang kami kembangkan memiliki response rate sekitar $52,7 \%$.

\subsection{Pengolahan Data Pribadi}

a) Jenis Kelamin

Pada studi tracer yang kami lakukan persentase dari jumlah responden berdasarkan jenis kelamin adalah $57,1 \%$ adalah laki-laki dan sisanya sebanyak $42,9 \%$ adalah perempuan.

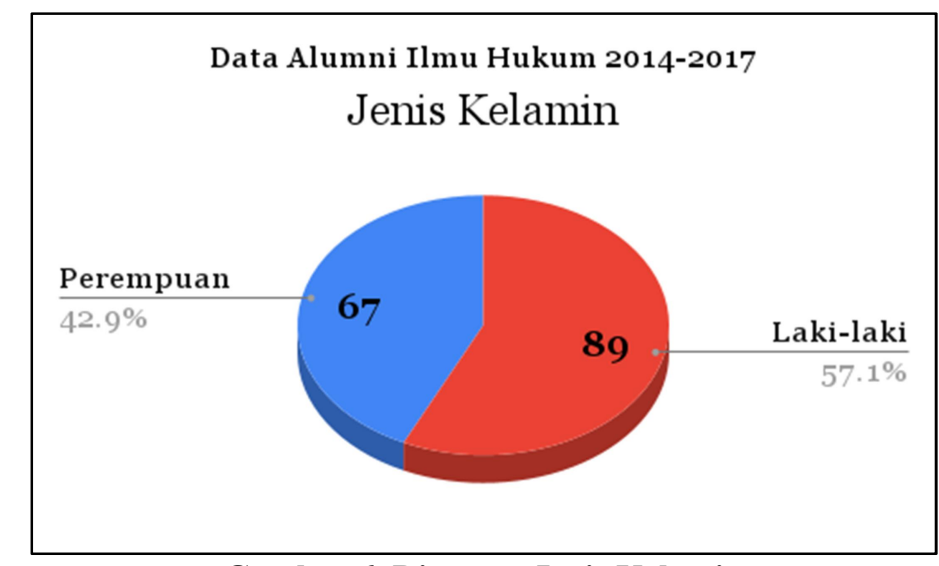

Gambar 6. Diagram Jenis Kelamin

b) Tahun Angkatan

Lalu untuk jumlah responden yang mengisi kuesioner memiliki persebaran angkatan dari rentang tahun antara 2012 hingga 2017. Untuk data lebih detail dapat dilihat pada Gambar 7. 


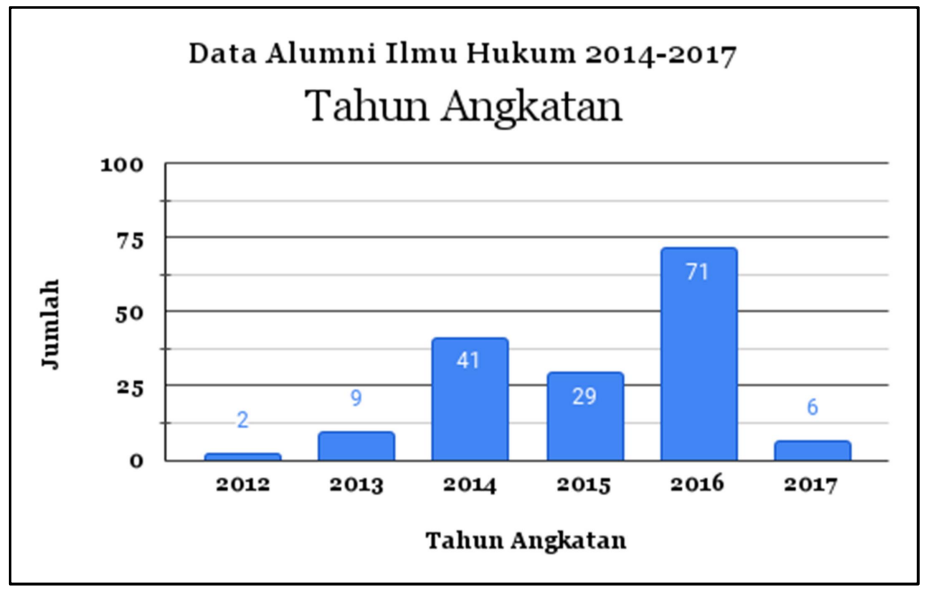

Gambar 7. Grafik Tahun Angkatan

c) Tahun Lulus

Sedangkan untuk kelulusan dari responden alumni memiliki persebaran tahun lulus dari rentang tahun antara 2018 hingga 2021. Alumni dengan tahun kelulusan 2018 yang menjawab kuesioner tercatat ada sejumlah 28 orang, lalu alumni yang lulus pada tahun 2019 sebanyak 25 orang. Catatan tertinggi diperoleh oleh kelulusan tahun 2020 yang mencapai 88 orang, selanjutnya yang terhitung lulus hingga bulan Juni 2021 terdapat 15 alumni yang menjawab kuesioner. Berdasarkan data status kelulusan, alumni yang lulus tepat waktu (tidak lebih dari 4 tahun) mencapai 111 orang, sedang yang lulus melebihi waktu 4 tahun adalah 45 orang. Data lebih jelas dapat dilihat pada Gambar 8.

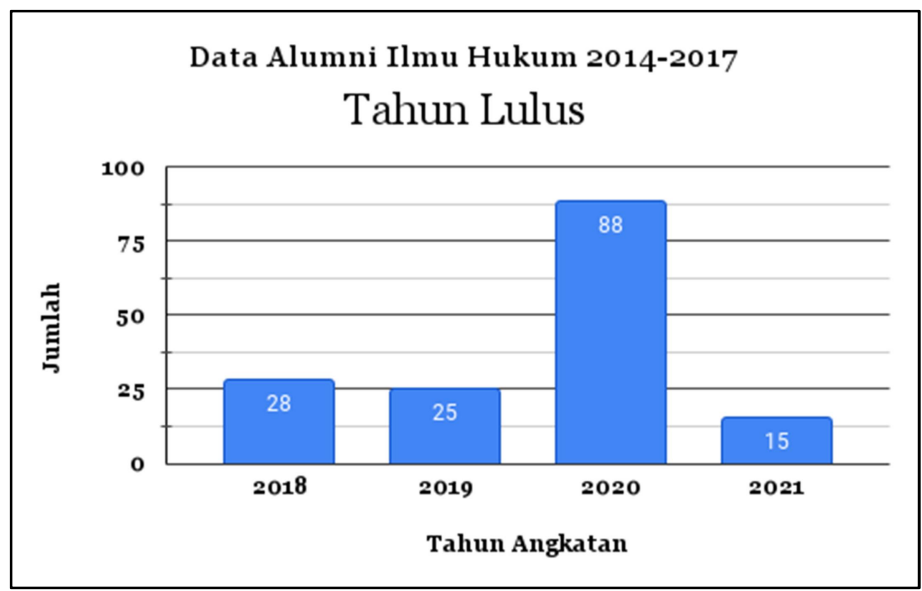

Gambar 8. Grafik Tahun Lulus

d) Status Perkawinan

Kemudian untuk status perkawinan dari alumni yang sudah dihimpun hingga saat ini memiliki hasil data dengan persentase sebanyak $87,8 \%$ sudah menikah, 10,9\% sudah menikah, dan sisanya sebanyak 1,3\% pernah menikah. 


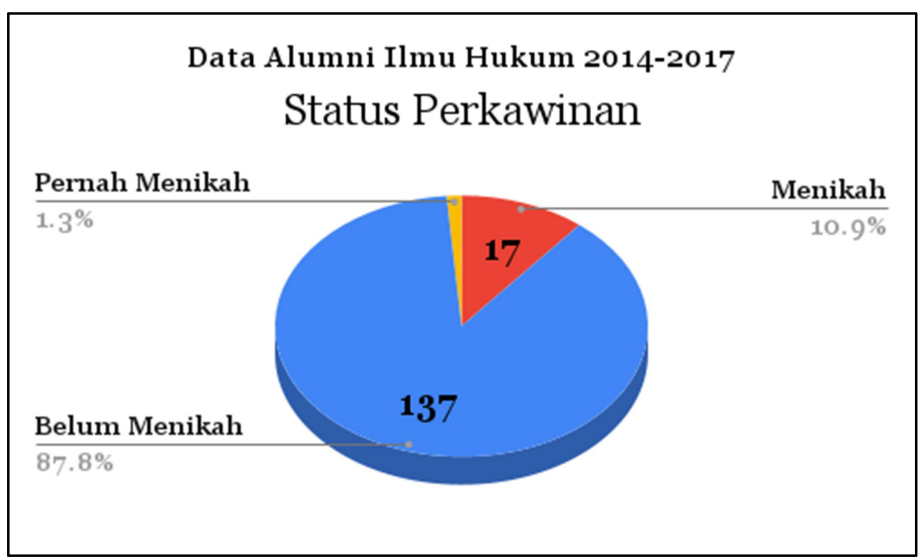

Gambar 9. Diagram Status Perkawinan

\subsection{Pengolahan Data Karir}

Data alumni setelah lulus memiliki persebaran data dengan 50,9\% telah bekerja, 16,8\% melanjutkan studi, 16,8\% berwirausaha, dan sisanya 15,6\% dalam masa tunggu bekerja.

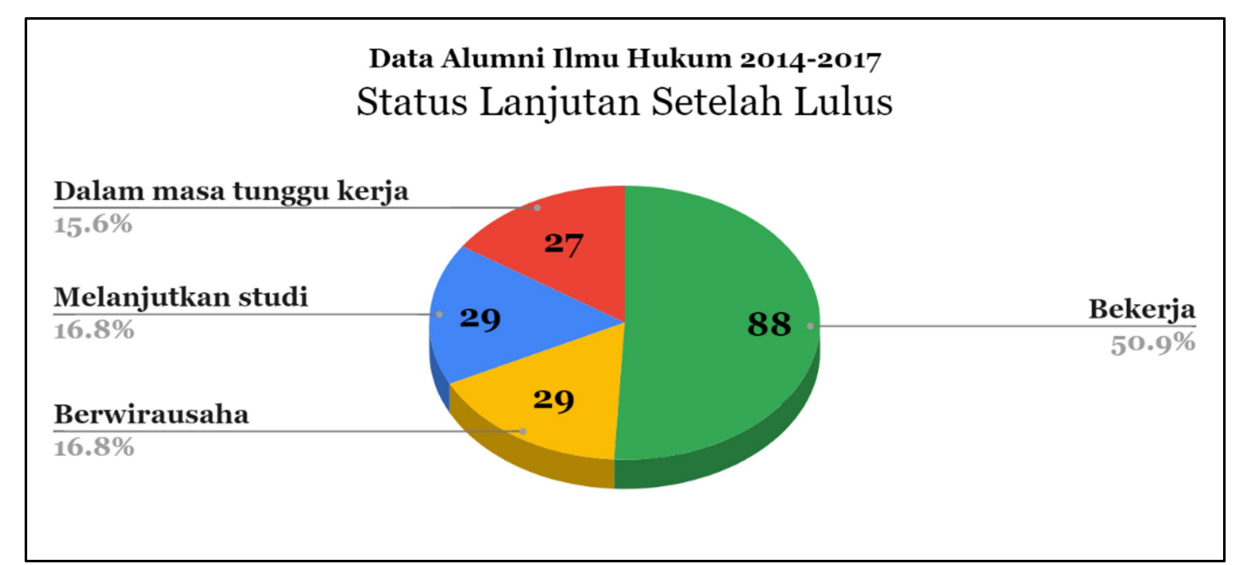

Gambar 10. Diagram Status Lanjutan Setelah Lulus

a) Studi Lanjut

Data dari alumni program studi Ilmu Hukum yang melanjutkan studi terdapat 16,8\% dari keseluruhan responden atau 29 orang dengan pembagian 28 orang mengambil pendidikan lanjut strata 2 (S2), dan 1 orang mengambil pendidikan profesi (pendidikan advokat). 


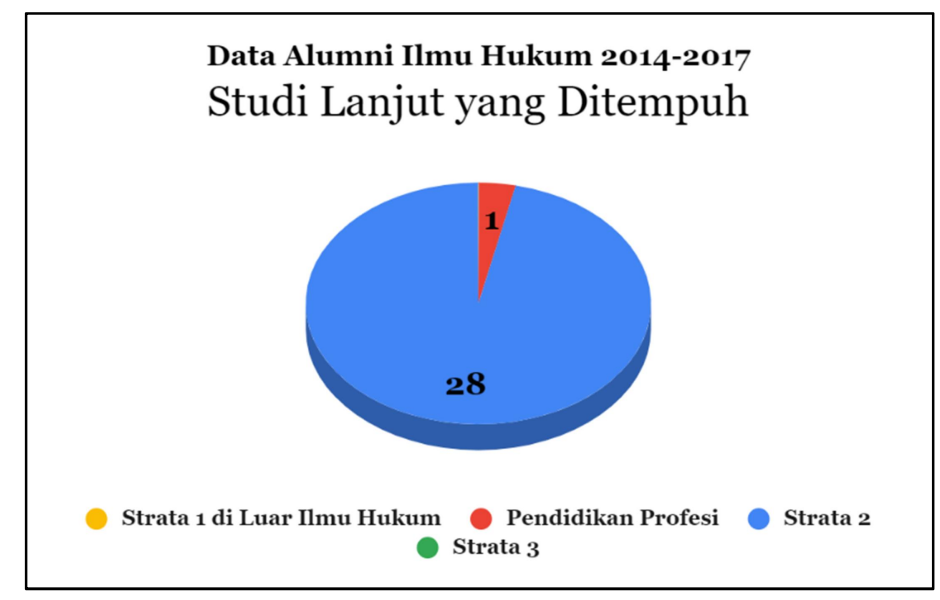

Gambar 11. Diagram Studi Lanjut yang ditempuh

b) Berwirausaha

Data dari alumni program studi Ilmu Hukum yang berwirausaha setelah lulus terdapat $16,8 \%$ dari keseluruhan responden atau 29 orang dengan bidang usaha yang beragam seperti terlihat pada Tabel 1 .

Tabel 1. Bidang Usaha

\begin{tabular}{clcc}
\hline No & \multicolumn{1}{c}{ Bidang Usaha } & Responden & Persentase \\
\hline 1 & Retail / perdagangan & 13 & $37.14 \%$ \\
2 & Jasa & 8 & $22.86 \%$ \\
3 & Kuliner & 5 & $14.29 \%$ \\
4 & Pakaian & 3 & $8.57 \%$ \\
5 & Pertanian dan peternakan & 2 & $5.71 \%$ \\
6 & Properti & 2 & $5.71 \%$ \\
7 & Kecantikan & 2 & $5.71 \%$ \\
\hline
\end{tabular}

Sedangkan untuk wirausaha yang dijalankan terdapat jenis usaha online sebanyak 56,25\% dan jenis usaha offline sebanyak 43,75\% dari keseluruhan responden yang berwirausaha.

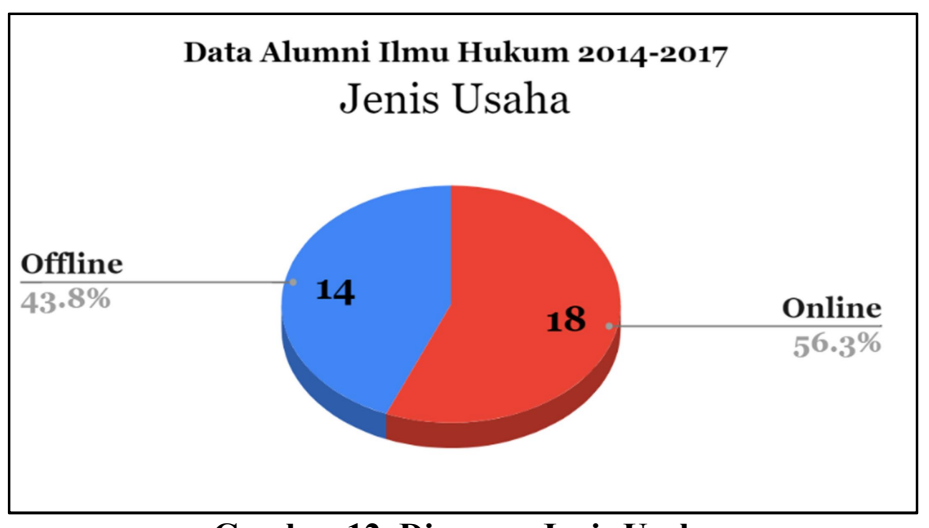

Gambar 12. Diagram Jenis Usaha 
c) Bekerja

Data dari alumni program studi Ilmu Hukum yang bekerja setelah lulus terdapat $50,9 \%$ dari keseluruhan responden dengan lembaga tempat bekerja yang bermacam-macam seperti yang diperlihatkan pada Tabel 2.

Tabel 2. Lembaga Tempat Bekerja

\begin{tabular}{clcc}
\hline No & \multicolumn{1}{c}{ Lembaga Tempat Bekerja } & Responden & Persentase \\
\hline 1 & Perusahaan Swasta & 52 & $56.52 \%$ \\
2 & Lembaga pemerintah (seperti PNS, BUMN) & 26 & $28.26 \%$ \\
3 & Organisasi Non-Profit (seperti LSM) & 3 & $3.26 \%$ \\
4 & Bukan lembaga, organisasi, maupun perusahaan & 2 & $2.17 \%$ \\
5 & Yayasan Pendidikan & 2 & $2.17 \%$ \\
6 & BUMD & 1 & $1.09 \%$ \\
7 & Kantor Advokat-Kurator & 1 & $1.09 \%$ \\
8 & Kantor Hukum & 1 & $1.09 \%$ \\
9 & Notaris & 1 & $1.09 \%$ \\
10 & Program Kementerian & 1 & $1.09 \%$ \\
11 & Universitas Negeri & 1 & $1.09 \%$ \\
12 & Wiraswasta & 1 & $1.09 \%$ \\
\hline
\end{tabular}

Kemudian dari data yang sudah dihimpun, bidang pekerjaan dari nonpemerintah atau swasta juga beragam mulai dari bidang hukum hingga pertanian dan peternakan, data rinci mengenai bidang pekerjaan yang berada di nonpemerintahan ada pada Tabel 3 .

Tabel 3. Bidang Pekerjaan (Non-Pemerintah)

\begin{tabular}{clcc}
\hline No & \multicolumn{1}{c}{ Bidang Pekerjaan (Non-Pemerintah) } & Responden & Persentase \\
\hline 1 & Hukum & 25 & $33.78 \%$ \\
2 & Informasi dan komunikasi & 9 & $12.16 \%$ \\
3 & Jasa professional, ilmiah, dan teknis & 9 & $12.16 \%$ \\
4 & Real estate, developer, dan properti & 6 & $8.11 \%$ \\
5 & Finance & 5 & $6.76 \%$ \\
6 & Pendidikan & 4 & $5.41 \%$ \\
7 & Perbankan & 4 & $5.41 \%$ \\
8 & Garmen & 2 & $2.70 \%$ \\
9 & Sales & 2 & $2.70 \%$ \\
10 & Sosial & 2 & $2.70 \%$ \\
11 & Agama & 1 & $1.35 \%$ \\
12 & Akuntansi & 1 & $1.35 \%$ \\
13 & Distribusi & 1 & $1.35 \%$ \\
14 & Ekspedisi & 1 & $1.35 \%$ \\
15 & Otomotif & 1 & $1.35 \%$ \\
16 & Pertanian dan peternakan & 1 & $1.35 \%$ \\
\hline
\end{tabular}

Lalu untuk skala lembaga tempat bekerja yang telah dihimpun dari para responden terdapat tiga skala yaitu lembaga lokal sebanyak 30,7\%, lembaga nasional sebanyak $51,1 \%$, dan lembaga internasional sebanyak 18,2\%. 


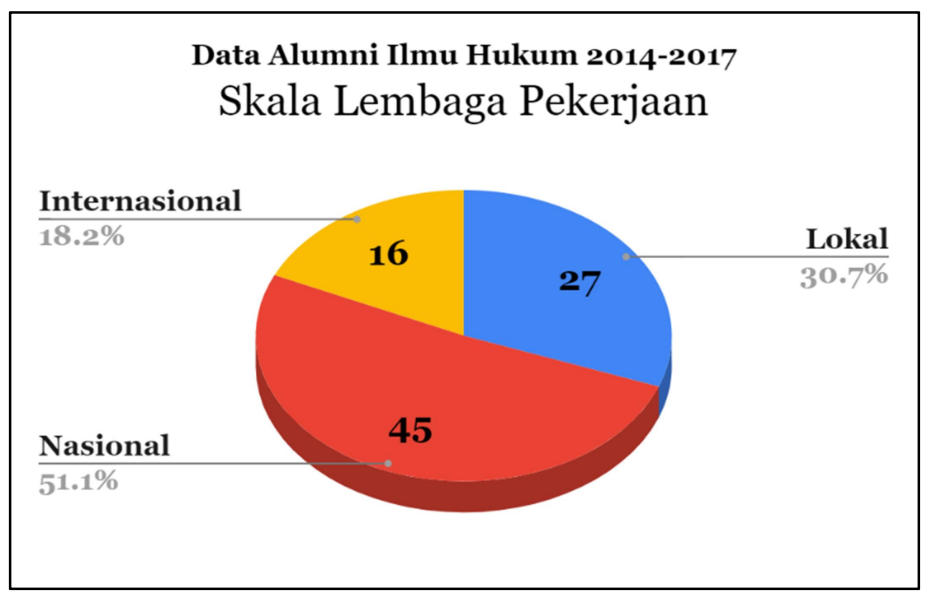

Gambar 13. Diagram Skala Lembaga Pekerjaan

Berdasarkan hasil tracer study pada alumni yang bekerja terdapat waktu tunggu setelah lulus hingga diterima bekerja yang beragam, mulai dari langsung bekerja setelah lulus bahkan sudah diterima bekerja sebelum lulus hingga menunggu 2 tahun hingga diterima bekerja, untuk persebaran data lebih jelasnya dapat dilihat pada Gambar 14.

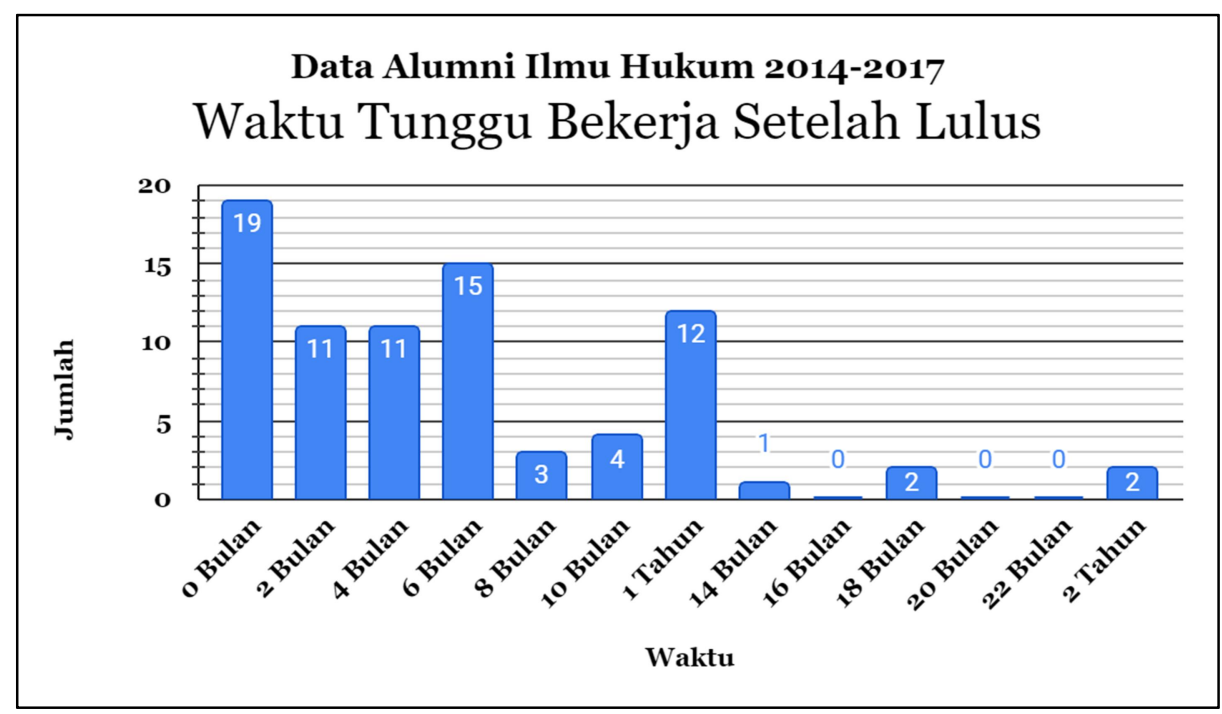

Gambar 14. Grafik Waktu Tunggu Bekerja Setelah Lulus

Tracer study untuk program studi Ilmu Hukum juga menghimpun data dari para responden tentang bagaimana cara memperoleh pekerjaan atau informasi awal mengenai pekerjaan tersebut seperti yang terlihat pada Tabel 4 . 
Tabel 4. Informasi Memperoleh Pekerjaan

\begin{tabular}{clcc}
\hline No & \multicolumn{1}{c}{ Lembaga Tempat Bekerja } & Responden & Persentase \\
\hline 1 & Melalui lamaran pada lowongan pekerjaan & 28 & $30.77 \%$ \\
2 & Melalui internet atau akun sosial media untuk job & 19 & $20.88 \%$ \\
& seeker & & \\
3 & Pemberi kerja / perusahaan menawarkan pekerjaan & 15 & $16.48 \%$ \\
4 & Melalui orang tua / keluarga & 12 & $13.19 \%$ \\
5 & Relasi & 9 & $9.89 \%$ \\
6 & Job fair & 2 & $2.20 \%$ \\
7 & Lain-lain & 6 & $6.59 \%$ \\
\hline
\end{tabular}

Berikutnya berdasarkan tracer study yang telah dilakukan mengenai kesesuaian keilmuan yang telah dipelajari dengan pekerjaan saat ini menyatakan bahwa perbandingan antara pekerajaan yang memiliki kesesuaian keilmuan dengan yang tidak memiliki kesesuaian ternyata tidak jauh berbeda, yaitu 48,9\% memilki kesesuaian dengan pekerjaan; sedangkan sisanya 51,1\% tidak memiliki kesesuaian dengan pekerjaan.

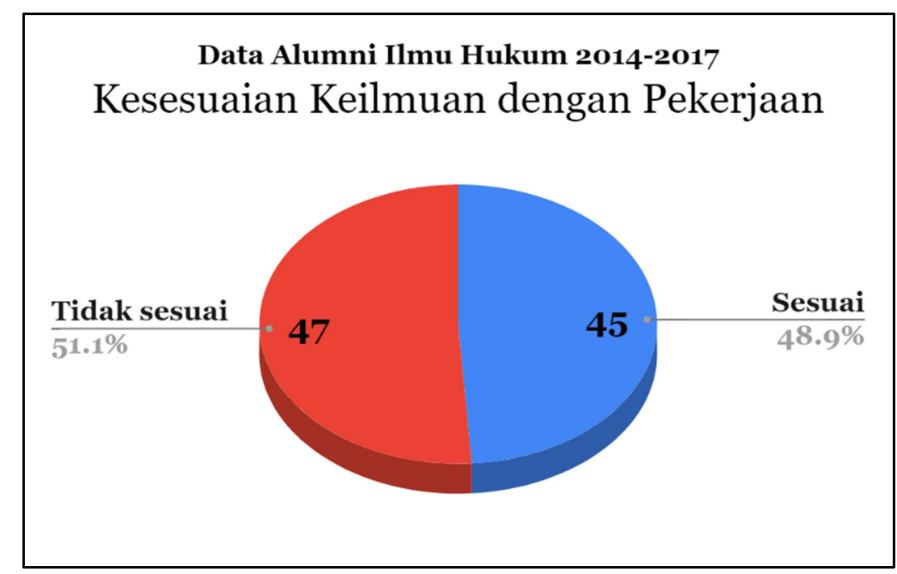

Gambar 15. Diagram Kesesuaian Ilmu dengan Pekerjaan

Data gaji per bulan dari alumni yang bekerja juga telah dikumpulkan dan hasilnya adalah lebih dari $75 \%$ responden memiliki gaji di bawah 5 juta, sedangkan sisanya sebanyak 19,4\% memiliki gaji 5-10 juta, 2,15\% memiliki gaji 10-20 juta, dan 1,08\% memiliki gaji di atas 20 juta.

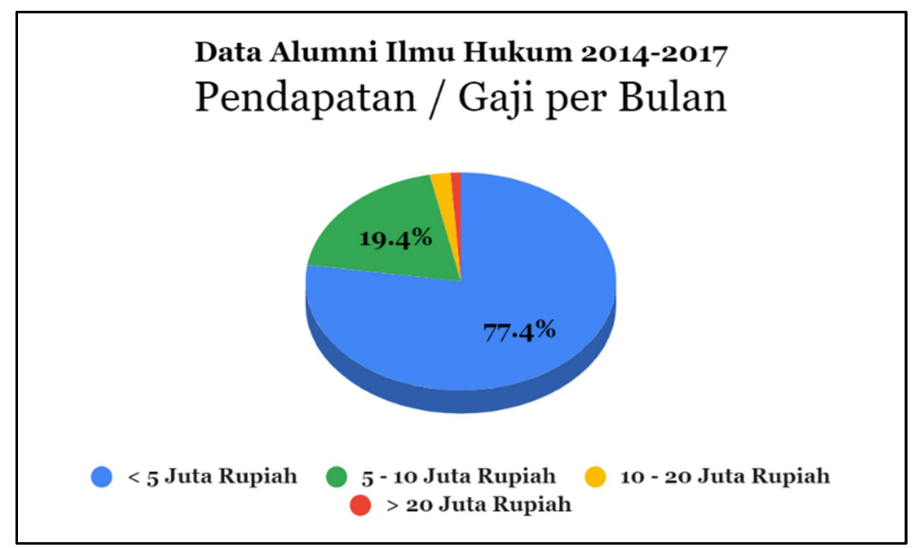

Gambar 16. Diagram Pendapatan/Gaji 


\subsection{Pengolahan Data Akademik}

a) Indeks Prestasi Kumulatif (IPK)

Persebaran IPK dari alumni yang sudah kami lakukan tracer menunjukan bahwa tidak ada alumni yang memiliki IPK di bawah 3,00, sedangkan untuk rata-rata IPK dari alumni adalah 3,59. Secara garis besar IPK dari alumni yang memiliki cakupan 3,01 - 3,50 sebanyak 23; sedangkan dengan cakupan 3,514,00 sebanyak 133. Informasi lebih detail mengenai persebaran data IPK alumni dapat dilihat pada Gambar 17.

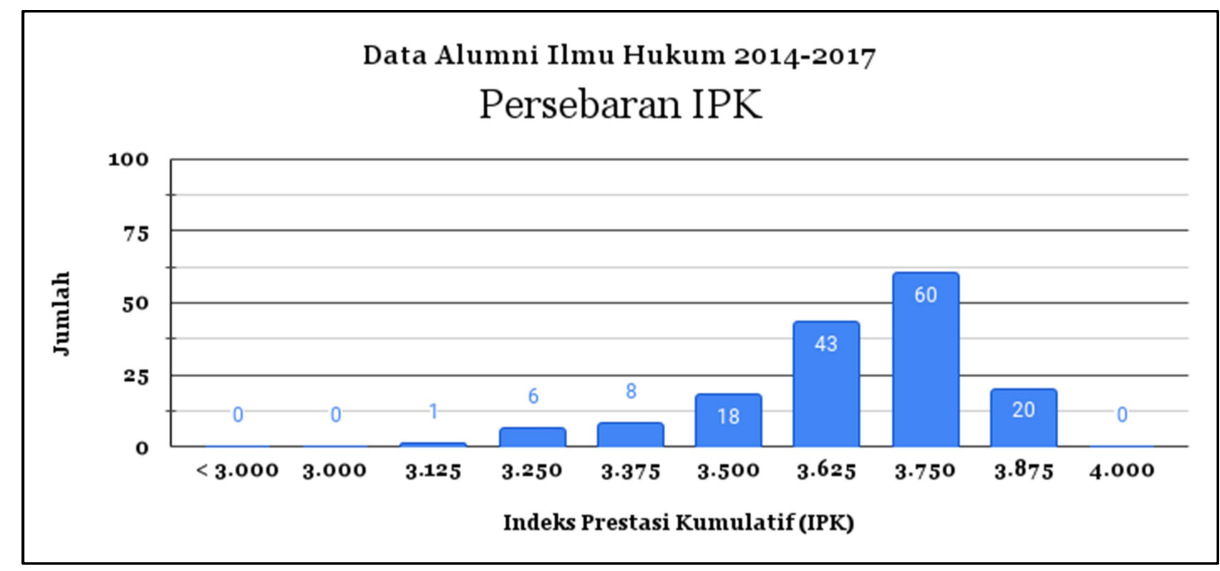

Gambar 17. Grafik Persebaran Indeks Prestasi Kumulatif (IPK)

b) Mata Kuliah yang Bermanfaat

Data dari mata kuliah yang telah dihimpun dari responden tracer studi alumni menghasilkan 10 mata kuliah teratas yang dinilai paling bermanfaat dan perlu dikembangkan. Mulai dari urutan pertama yaitu Hukum Perdata, Hukum Pidana, Pengantar Ilmu Hukum, Hukum Acara Pidana, Hukum Perancangan Kontrak, Legal Drafting, Hukum Acara Perdata, Hukum Agraria, Hukum Tata Negara, Hukum Internasional, untuk lebih jelasnya mengenai persebaran datanya sebagaimana terlihat pada Tabel 15 .

Tabel 5. Mata Kuliah Teratas yang Bermanfaat

\begin{tabular}{clcc}
\hline No & \multicolumn{1}{c}{ Mata Kuliah } & Responden & Persentase \\
\hline 1 & Hukum Perdata & 30 & $8.88 \%$ \\
2 & Hukum Pidana & 28 & $8.28 \%$ \\
3 & Pengantar Ilmu hukum & 24 & $7.10 \%$ \\
4 & Hukum Acara Pidana & 18 & $5.33 \%$ \\
5 & Hukum Perancangan Kontrak & 17 & $5.03 \%$ \\
6 & Legal Drafting & 16 & $4.73 \%$ \\
7 & Hukum Acara Perdata & 14 & $4.14 \%$ \\
8 & Hukum Agraria & 12 & $3.55 \%$ \\
9 & Hukum Tata Negara & 12 & $3.55 \%$ \\
10 & Hukum Internasional & 11 & $3.25 \%$ \\
\hline
\end{tabular}


c) Status Kelulusan

Dari hasil tracer study tahun yang dilakukan untuk alumni program stdui Ilmu Hukum dengan responden alumni tahun 2012 hingga 2017 diketahui bahwa sebanyak $71,2 \%$ lulus tepat pada waktunya atau masa studi tidak lebih dari 4 tahun, sedangkan untuk sisanya 28,8\% lulus dengan masa studi lebih dari 4 tahun.

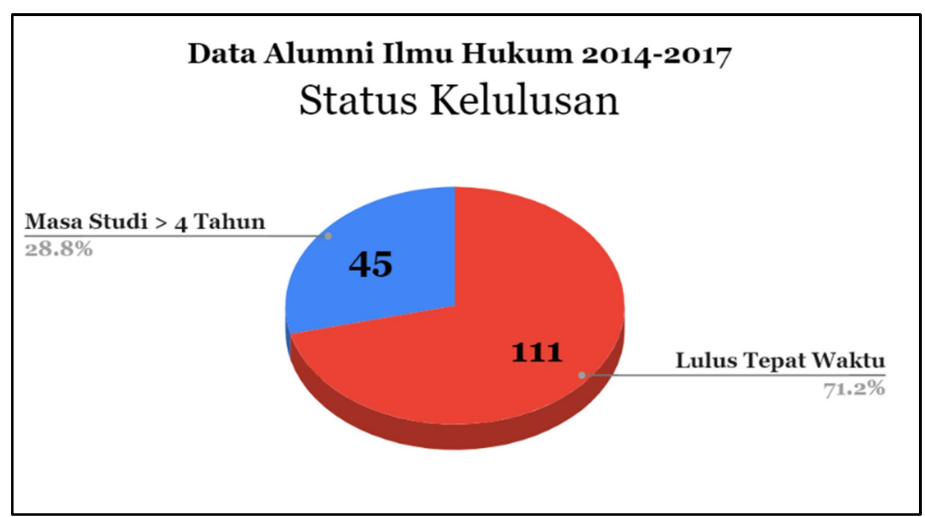

Gambar 18. Diagram Status Kelulusan

\subsection{Pengolahan Data Penilaian Kegiatan Belajar Mengajar (KBM)}

Penilaian dari proses belajar mengajar selama perkuliahan pada tracer studi mencakup kegiatan pembelajaran, fasilitas belajar, dan pengalaman belajar. Penilaian pada kegiatan belajar dibagi atas empat indikator mulai dari tinggi hingga rendah yaitu, "baik sekali”, “baik”, “cukup”, dan "kurang”.

a) Penilaian Pembelajaran

Berdasarkan hasil tracer studi menunjukan bahwa lebih dari 50\% alumni merespon kegiatan pembelajaran yang dilakukan selama perkuliahan dengan nilai yang "baik". Kemudian sisanya "baik sekali" sebanyak 15,4\%, "cukup" sebanyak 23,7\%, dan "kurang" sebanyak 2,6\%.

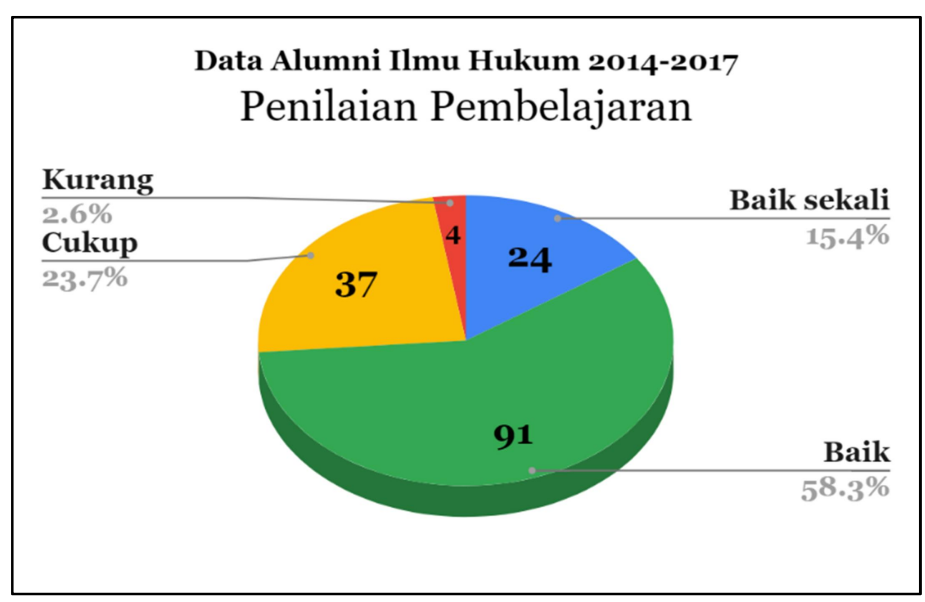

Gambar 19. Diagram Penilaian Pembelajaran 
b) Penilaian Fasilitas Belajar

Hasil tracer study yang dilakukan pada fasilatas belajar memperlihatkan bahwa sebanyak 10,9\% menilai dengan respon "baik sekali”, lalu respon "baik" sebanyak 42,9\%, respon "cukup" sebanyak 31,4\%, dan respon "kurang" sebanyak $14,7 \%$.

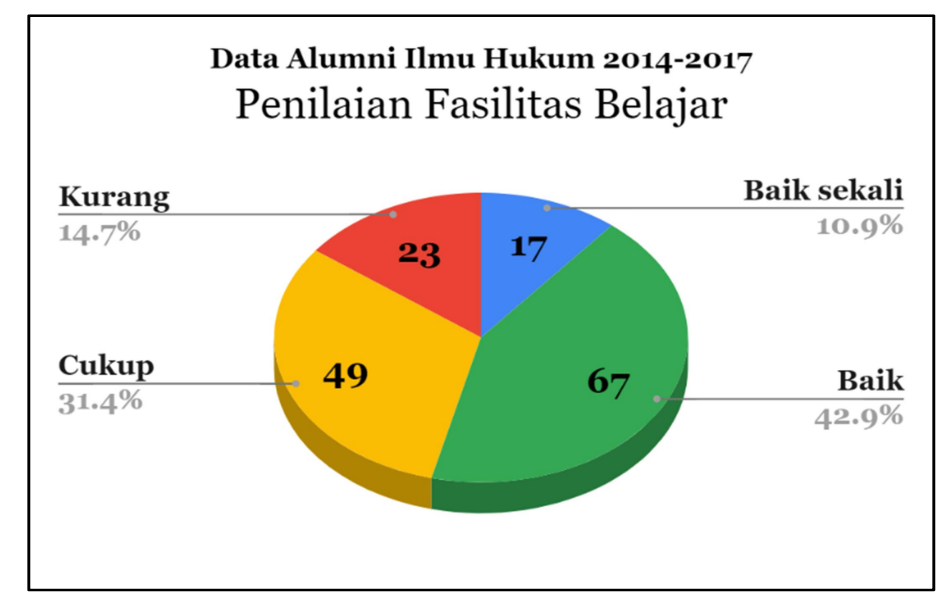

Gambar 20. Diagram Penilaian Fasilitas Belajar

c) Penilaian Pengalaman Belajar

Terakhir adalah penilaian pada pengalaman belajar alumni selama menjadi mahasiswa di program studi Ilmu Hukum menunjukan bahwa lebih dari 50\% memberi tanggapan "baik". Kemudian sisanya "baik sekali" sebanyak 17,3\%, “cukup" sebanyak 24,4\%, dan "kurang” sebanyak 14,7\%.

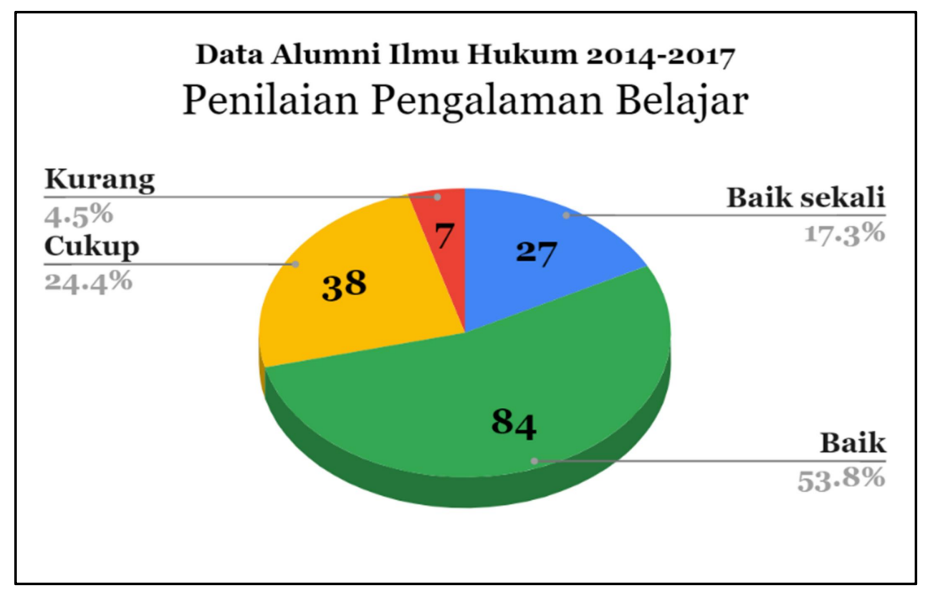

Gambar 21. Diagram Pengalaman Belajar

Tahapan penyelesaian dari program tracer study alumni adalah penyerahan laporan kepada pihak Program Studi Ilmu Hukum. Laporan ini berisikan data yang telah dihimpun dari jawaban-jawaban kuesioner. Data alumni kemudian dapat dijadikan bahan evaluasi bagi program studi untuk meningkatkan proses belajar mengajar, sehingga dapat menciptakan lingkungan pendidikan yang bermanfaat bagi masyarakat dan menciptakan 
para sarjana-sarjana hukum yang berintegritas tinggi dengan tetap memegang teguh nilainilai syari'ah.

\section{KESIMPULAN DAN SARAN}

Berdasarkan tahapan yang telah dilakukan pada program tracer study, yaitu mulai dari Penyusunan Kuesioner Online, Pendataan Alumni dan Informasi Kontak, Pengisian Kuesioner, Pembuatan Akun Media Sosial Alumni Ilmu Hukum, hingga Pengolahan Data memberikan pemahaman bagaimana cara melakukan kegiatan tracer study untuk alumni secara daring. Lebih daripada itu, tujuan kegiatan ini secara umum dilakukan untuk memberikan pengetahuan dan informasi mengenai hasil pendidikan dan kompetensi lulusan dengan dunia kerja juga menjaring alumni yang masih dalam tahap pencarian kerja atau melanjutkan pendidikan.

Dari penilaian yang sudah dilakukan terhadap tiga hal di atas, yaitu penilaian pembelajaran, penilaian fasilitas belajar, dan penilaian pengalaman belajar memperlihatkan bahwa penilaian terhadap fasilitas belajar memiliki respon "kurang" dengan porsi yang paling besar jika dibandingkan dengan dua penilaian lainnya.

Saran yang bisa penulis sampaikan adalah pihak prodi perlu meningkatkan kualitas dari sisi fasilitas belajar agar dapat menunjang kegiatan perkuliahan mahasiswa lebih baik lagi untuk kedepannya.

\section{UCAPAN TERIMA KASIH}

Ucapan terima kasih kami sampaikan kepada Fakultas Syari'ah dan Hukum UIN Sunan Kalijaga, khususnya Program Studi Ilmu Hukum atas kesempatan yang diberikan kepada kami untuk melakukan tracing alumni yang telah diselenggarakan dari tanggal 13 Juli - 5 Agustus 2021. Selanjutnya, ucapan terima kasih yang sedalam-dalamnya kepada alumni Ilmu Hukum UIN Sunan Kalijaga yang telah turut serta berpartisipasi sehingga mensukseskan kegiatan tracing. Terima kasih pula kepada Dosen Pembimbing Lapangan kami, Bapak Faiq Tobroni, M.H., yang telah setia memberikan arahan dan masukan selama kegiatan KKN. Teruntuk teman-teman satu tim KKN 105 Tracer FSH, terima kasih atas kerja samanya yang memungkinkan semua program kerja ini berjalan. 


\section{DAFTAR PUSTAKA}

Dorji, Namgay. 2020. Tracer Study: An analysis of 2018 Graduates of Gedu College of Business Studies, Bhutan. International Journal of Advanced Science and Technology, 29(6) 1680-1686.

Fajaryati, Nuryake, Priyanto, Totok Sukardiyono, Athika Dwi Wiji Utami, Sigit Pambudi, and Bonita Destiana. 2015. Studi Penelusuran (Tracer Study) Terhadap Alumni Program Studi Pendidikan Teknik Informatika Jurusan Pendidikan Teknik Elektronika Fakultas Teknik Universitas Negeri Yogyakarta. Jurnal Electronics, Informatics, and Vocational Education (ELINVO), 1(1): 44-48.

Kansil. 1989. Pengantar Ilmu Hukum dan Tata Hukum Indonesia. Jakarta: Balai Pustaka. 